\title{
Nasal Tip Drop After Rhinoplasty Resulting from The Excessive Use of Masks: A New Complication in The Covid-19 Pandemic?
}

\author{
Merkle A, ${ }^{1 *}$ Luci Fernandes B, ${ }^{2}$ Dewes W, ${ }^{3}$ de Souza Seabra KA, ${ }^{4}$ Fernando Ferreira , $^{5}$ Magno Gonçalves $\mathrm{MV}^{6}$ \\ ${ }^{1}$ Otolaryngologist-Department of Health Technology, Pontifical Catholic University of Paraná (CURITIBA), Brazil \\ ${ }^{2}$ Professor of Health Technology-Pontifical Catholic University of Parana (CURITIBA), Brazil \\ ${ }^{3}$ Otolaryngology \& Head and Neck Surgery specialist, Facial Plastic Surgeon-Dewes Clinic for Facial Plastic Surgery (LAJEADO), Brazil \\ ${ }^{4}$ Otolaryngologist-Dewes Clinic for Facial Plastic Surgery (LAJEADO), Brazil \\ ${ }^{5}$ Professor of Neurology-Department of Medicine, University of the Region of Joinville (JOINVILLE), Brazil \\ ${ }^{6}$ Professor of Otolaryngology-Department of Medicine, University of the Region of Joinville (JOINVILLE), Brazil
}

Keywords: Tip ptosis, Dropping nose, Post rhinoplasty

\section{Editorial}

Postoperative dropping of the nasal tip after rhinoplasty is a known complication. ${ }^{1}$ Defining the position of the nasal tip begins with stabilizing the nasal base. ${ }^{2}$ To define the position of the nasal tip and stabilize the nasal base of the nose, the surgeon has three main options: tongue-in-groove maneuver, ${ }^{3}$ caudal septal extension graft, or columellar strut. ${ }^{4,5}$

Significant loss of rotation is expected during the first year and surgeons need to over-correct tip rotation to compensate for this loss. In a recent study, Antunes and Quatela ${ }^{6}$ identified patients who were submitted to a rhinoplasty with a tong-in-groove maneuver over a period of 1 year, and demonstrated an average reduction in the nasolabial angle of $6.8 \%$, estimating that for each degree of rotation changed at surgery, the patient will have a loss of 0.35 degrees over the first year.
Despite the routine use of techniques to structure the nasal tip in rhinoplasties, we have observed an increase in the incidence of nasal tip fall in patients who underwent functional and aesthetic rhinoplasty before the covid 19 pandemic and who are now carrying out the 6-month postoperative evaluation.

We selected the last 20 patients who underwent rhinoplasty in the months of November and December 2019 and compared the measurements of the nasolabial angle immediately after surgery and 6 months after surgery. We observed that 14 patients $(70 \%)$ showed a decrease between 10 and 15 degrees in the naso labial angle 6 months after surgery, which is not consistent with our results observed over the past years (unpublished).

To date, we do not know published data on nasal ptosis after rhinoplasty due to the excessive use of masks. We are concerned that there may be a progressive increase in the severity of these

\begin{tabular}{l|l}
\hline Quick Response Code: & Porresponding author: Anderson Merkle, Otolaryngologist, Department of Health Technolo- \\
gy, Pontifical Catholic University of Paraná (CURITIBA), Brazil \\
Received: 07 August, 2021 \\
Citation: Merkle A, Fernandes LB, Dewes W, Souza Seabra KA, Ferreira FR, et al. Nasal Tip \\
Drop After Rhinoplasty Resulting from The Excessive Use of Masks: A New Complication \\
in The Covid-19 Pandemic? Mod Res Plast Recon Sur. 2021;1(3):1-2. DOI: 10.53902/MR- \\
PRS.2021.01.000514
\end{tabular}


cases due to the routine use of masks and the need for even greater support of the nasal tip in patients who will undergo rhinoplasty in the future, believing that wearing masks can become a new habit in patients' lives.

\section{Acknowledgments}

None.

\section{Funding}

None.

\section{Conflicts of Interest}

Authors declare that there is no conflict of interest.

\section{References}

1. Fred GB. Postoperative Dropping of the Nasal Tip After Rhinoplasty. Archives of Otolaryngology-Head and Neck Surgery. 1958;67(2):177-181.
2. Tardy ME. Rhinoplasty tip ptosis: etiology and prevention. Laryngoscope. 1973;83(6):923-929.

3. Toriumi DM. Nasal Tip Contouring: Anatomic Basis for Management. Facial Plastic Surgery \& Aesthetic Medicine. 2020;22(1):10-24.

4. Kridel RW, Scott BA, Foda HM. The tongue-in-groove technique in septorhinoplasty. A 10-year experience. Arch Facial Plast Surg. 1999;1(4):246-56.

5. Toriumi DM. Caudal septal extension graft for correction of the retracted columella. Op Tech Otol Head Neck Surg. 1995;6(4):311-318.

6. Byrd HS, Andochick S, Copit S, et al. Septal extension grafts: a method of controlling tip projection shape. Plast Reconstr Surg. 1997;100(4):999-1010.

7. Antunes MB, Quatela VC. Effects of the Tongue-in-Groove Maneuver on Nasal Tip Rotation. Aesthet Surg J. 2018;38(10):1065-1073. 